\title{
Improved Artificial Neural Network Grid Synchronization Technique for Three-Phase Grid Systems based on Synthesis Segmental Multilevel Converter
}

\author{
${ }^{I}$. Nirmala.R, Ph.D Scholar, Dept. of EEE, A.C. Govt. College of Engineering and Technology, Karaikudi, \\ India.Email: nirmala21harsha@gmail.com \\ 2. Venkatesan.S, Assistant Professor Dept. of EEE, A.C.Govt. College of Engineering and Technology, \\ Karaikudi, India. Email:venkateee10@gmail.com
}

\begin{abstract}
The solar Photovoltaic (PV) systems have gained a significant attention due to its easy implementation and availability. In which, the proper energy management should be mainly concentrated for a successful PV power utilization. In the traditional works, various controlling techniques have been developed for reactive power compensation. But, it lacks with the issues related to reduced system performance, increased loss, and high harmonics. To solve these issues, this paper aims to develop a new controlling methodology, named as Synthesis Segmental Multilevel Converter (SSMC) for reactive power compensation in a three phase grid systems. Initially, it extracts the maximum power from the solar PV systems by using an Enhanced Perturb and Observe (EPO) method. The panel separation is done and the three phase power input is given to the SSMC converter, where the synchronization and switching pulse generation processes are performed. During synchronization, integrated techniques such as Proportional Integral (PI), Fuzzy Logic Controller (FLC), and Improved Artificial Neural Network (IANN) techniques are utilized to maintain the voltage, magnitude and phase angle in a same level. Consequently, the Inductance Capacitance (LC) filtering technique is applied to reduce the harmonics distortion in the signal. After that, the Park transformation is used to perform the dq0 to abc transformation, which is implemented for reducing the high volume of error. Finally, the error free signal is fed to the three phase grid system with reduced harmonics also both the simulation and analytical results have been taken for analyzing the performance of the proposed technique.

Index Terms - Renewable Energy Sources (RES), Photovoltaic (PV) systems, Synthesis Segmental Multilevel Converter (SSMC), Maximum Peak Point Tracking (MPPT), Reactive Power Compensation, and Synchronization.
\end{abstract}

\section{Introduction}

In the recent decades, the Renewable Energy Sources (RES) plays a vital role in a power distribution systems, which includes a solar energy and wind energy Yang et al. (2019). But, the output power of these systems are mainly depends on the weather and climatic conditions of the environment. The Photovoltaic (PV) systems are the kind of solar energy sources Shen,et al. (2017); Gandhi et al. (2017) which offers the electrical power to the grid systems Oshi and Arora (2017). The major benefit of using PV systems are, it deals with the best economic solutions for offering the required power supply Aktas et al. (2018). Due to its attractive nature, it is widely applied in most of the power generation systems Elseroug and Ahmed (2016), Téllez et al. (2018) Owing to varying isolation and operating temperature, the individual PV modules are exposed to different environmental conditions Mohamed and Diab (2019). So, it is highly 
essential to guarantee the optimal performance of each modules presented in the PV array Verma and Singh (2020). In order to ensure the system stability in a grid connected systems, the efficiency of the PV panels are improved with the power conversion Nemet et al. (2017), Ozbay and Oncu (2017). Moreover, the maximum powers from the PV panels are withdrawn under different weather and load conditions.

Typically, the three phase inverter is the elementary component of the grid connected solar PV systems, which has the responsibility to convert the input DC to AC power with same frequency, angle and amplitude Zhang et al. (2018), Gandhi et al. (2018). Also, it ensures the validity and reliability of the loads on the power grid systems Mahfuz-Ur-Rahman et al. (2018). The proficiency of the energy transfer can be guaranteed based on the gain of voltage sag, swell and power factor Kurtoğlu et al.(2019), Kraiczy and Stetz (2017). Some of the traditional works developed a multilevel converters Behera and Thakur (2017) for increasing the quality of voltage and current in the power systems. But, it limits with the issues of increased harmonics distortion and number of switching devices Kolhe and Rasul (2020). In order to assure the better power quality with reduced harmonics, a standard controlling technique is required for extracting the maximum power from the PV systems Yaramasu and Dekka, (2021). Thus, this paper intends to develop a new controlling strategy, named as SSMC for the compensation of reactive power in a grid systems with reduced computation complexity Li et al. (2017). Also, it deals with the design and performance analysis of the three phase converter topology for improving the dynamic performance of the PV systems. The major objectives behind this work are listed as follows;

- To improve the power quality generation in the PV systems, the Maximum Peak Point Tracking (MPPT) controlling algorithm is utilized.

- To reduce the number of switching devices and its stress, the H-Bridge converters are used.

- To compensate the reactive power in an efficient manner, a Synthesis Segmental Multilevel Converter (SSMC) strategy is implemented with the synchronization methodology.

- To simultaneously increase the voltage and current quality with reduced harmonics, a three phase converter design is presented.

The rest of sections present in the paper are organized as follows: the traditional works related to the generation of solar power are surveyed with its own merits and demerits in Section II. The overall working procedure of the proposed methodology is presented with its detailed illustration in Section III. The experimental and simulation results of the proposed converter topology are validated in Section IV. Finally, the paper is concluded with its future direction in Section V.

\section{Related works}

This section surveys the existing techniques related to the converter and controller topologies for solar power integration. Also, it studies the advantages and disadvantages of each technique for improving the power generation in grid systems. Basu and Maiti (2019) introduced a Hybrid Modular Multilevel Converter (H-MMC) for improving the power quality of solar PV systems. The main aim of this paper was to attain the maximum power tracking of PV systems by incorporating the functionalities of MPPT with the H-MMC technique. Also, the Low Pass 
Filtering (LPF) technique was applied to eradicate the harmonics in the input signals. In addition to that, the problem of power unbalancing was resolved in this work by deploying the intra-phase and inter-phase partial shading approaches. The advantage behind this controller was the suitability of high power applications. Dutta et al. (2017) suggested a bidirectional inverter named as, buck and boost for simultaneously extracting the maximum power from the grid connected PV systems. Here, the controller was mainly implemented for the following reasons: distinguishing the output voltage and the sub-arrays could be operated based on the MPP. Moreover, the polypropylene film capacitors have been utilized in this system for measuring the leakage current. The advantages of the suggested inverter were better operating efficacy, decoupled controlling, and reduced leakage current.

Liu et al. (2019) recommended a distribution control strategy with hybrid energy sources for avoiding fault tolerance. Here, the fault tolerance was attained by the use of redundant converter and bypassing the faulty converter. The intention of this work was to improve both the system reliability and stable operation. The simulation results of this work stated that the suggested controller was more suitable for the cascaded multilevel systems due to its easy implementation and dynamic response. Libo et al. (2007) deployed an MPPT mechanism for performing a reactive power compensation in a grid connected PV systems. The intention of this work was to reduce the step length of output power reference by estimating the maximum peak point. In the modified MPPT mechanism, the PV panels could be operated in both voltage source region and current source region. Altawallbeh et al. [2019] implemented an Average Value Model (AVM) for ensuring the stability, reliability and efficiency of the power system. In addition to that, a reactive power compensation method was utilized to reduce the voltage sag on grid. Here, the MMC could be modeled based on the fast switching actions with trivial integration time. Moreover, the LCL filtering technique was employed to reduce the harmonics in the output current.

Prasad et al. (2018) deployed an adaptive hysteresis current control scheme for reactive power compensation in a grid systems. Moreover, a Synchronous Reference Frame (SRF) method was applied to extract the reference current for inverter switching. Also, the maximum power was extracted from the PV panel with the help of Perturb Observer (P\&O) and MPPT schemes. The main drawback behind this work was, it required to reduce the harmonics in the output power due to the nonlinear load. Yang et al. (2020) developed a Hybrid Cascaded Inverter (HCI) by incorporating the functionalities of LCC and MMC topologies. This technique intends to guarantee the stable operation of the system by using the reactive power compensation strategy. Moreover, the safe operation of the system was ensured with the help of restart strategy. Still, it limits with the issues like increased computational and time complexity.

Mukundan et al. (2020) established a Binary Hybrid Multilevel Inverter (BHMLI) for an efficient solar energy conversion system. Also, an Incremental Conductance (IC) algorithm with MPPT was utilized to extract the maximum power from the solar PV systems. The major considerations of this work were real and reactive power control, source current balancing and harmonics elimination. Here, the efficiency of the suggested inverter was validated with respect to the switching states, and total loss of semiconductor devices. Busarello et al. (2017) recommended a three phase Battery Storage System (BSS) for a distributed power grid systems, which was constructed with the help of $8 \mathrm{H}$-bridge converters. In this model, the Root Mean Square (RMS) value of the voltage and current at output terminal has been calculated for analyzing the detection of failure. Also, the State of Charge (SOC) was estimated for analyzing 
the average current of all batteries. The merits of the BSS were better reliability and uninterrupted supply to the distribution systems.

Muneer and Bhattacharya (2018), a Unified Power Quality Conditioner(UPQC) was employed to resolve the power quality issues, which includes voltage sag, reactive power compensation and power unbalancing. The UPQC was split into the categories of series and shunt filter control by the use of feedback control theory. The voltage unbalancing problem was resolved by using the SRF control circuit. Still, this paper requires to prove the superiority of the suggested mechanism by validating the error measures. Ramya et al. (2019) presented an Interleaved Boost Converter (ILBC) for improving the power quality of PV systems. In this paper, various controlling techniques have been compared with the ILBC based on the closed loop analysis, which depicted the better dynamic response of the system. In addition, the switching pulses of the power system were generated by the use of Stepped Pulse Width Modulation (SPWM) technique. The major advantages of this work were improved efficiency, current gain, and reduced switching. Mantila et al. (2021) endorsed a signal generation algorithm for solving the problems of current harmonics elimination, power factor correction and load balancing. Here, the grid voltage and current reference were determined with the help of an adaptive Butterworth-Kalman filtering and Fryze's theory. Moreover, it offered a minimum RMS value by ensuring an optimal power exchange between the load and grid.

Ou et al. (2016) developed a Transient Voltage Control (TVC) scheme for improving the voltage stability of the grid connected systems. The intention of this scheme was to increase the output reactive power and stator voltage level in an efficient manner. Mortezaei et al. (2018) presented a Cascaded Mutilevel Converter (CMC) for increasing the flexibility of power conditioning in the smart grid systems. The Conservative Power Theory (CPT) was employed to analyze the load characteristics of the power systems. The suggested converter topology aimed to solve the problems of low THD, Electromagnetic Interference (EMI), reduced switching losses and power quality. Renukadevi and Jayanand (2015) introduced a synchronous reference frame strategy for compensating the harmonics and reactive power to the grid systems in an efficient way. The co-ordinate transformations were utilized to isolate the harmonics and reactive power from the load current. The limitation behind this work was, it required to increase the efficiency of the system by deploying an operative converter and inverter topologies.

\section{Proposed methodology}

This paper proposed a Synthesis Segmental Multilevel Converter (SSMC) for extracting the maximum power from the solar PV systems with reduced harmonic distortion. For this purpose, improved controlling methodologies such as PI, fuzzy, and IANN have been implemented in this work. The major advantages of using SSMC with MPPT techniques are as follows: reduced harmonics, improved power quality, reduced number of switching and its stress. The stages involved in this strategy are given as below:

- Power extraction

- Converter Design

- Filtering

- Transformation

The overall flow and block representation of the proposed SSMC design is illustrated in Fig 1 and 2, in which 6 distinct panels have been connected under the R, Y and B phases. Then, its output power is considered as the real power current, which is given into the input of RL and RC filtering technique for reducing the harmonic level. Furthermore, the $\mathrm{dq} 0$ and abc transformation 
could be applied to reduce the high volume of error, and the converted signals are given to the three phase grid systems. The detailed working description is illustrated in the following subsections.

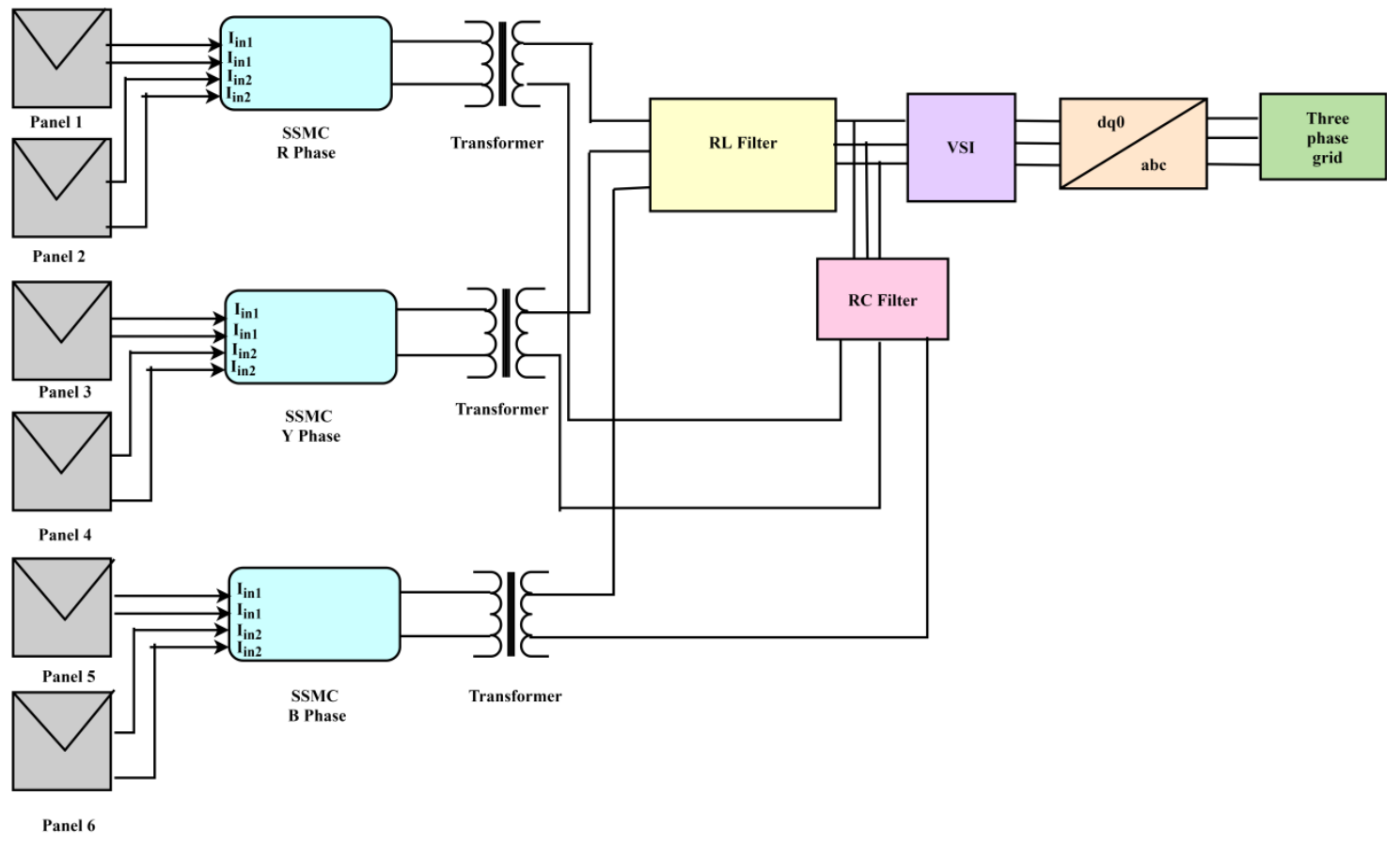

Fig 1. Block diagram 


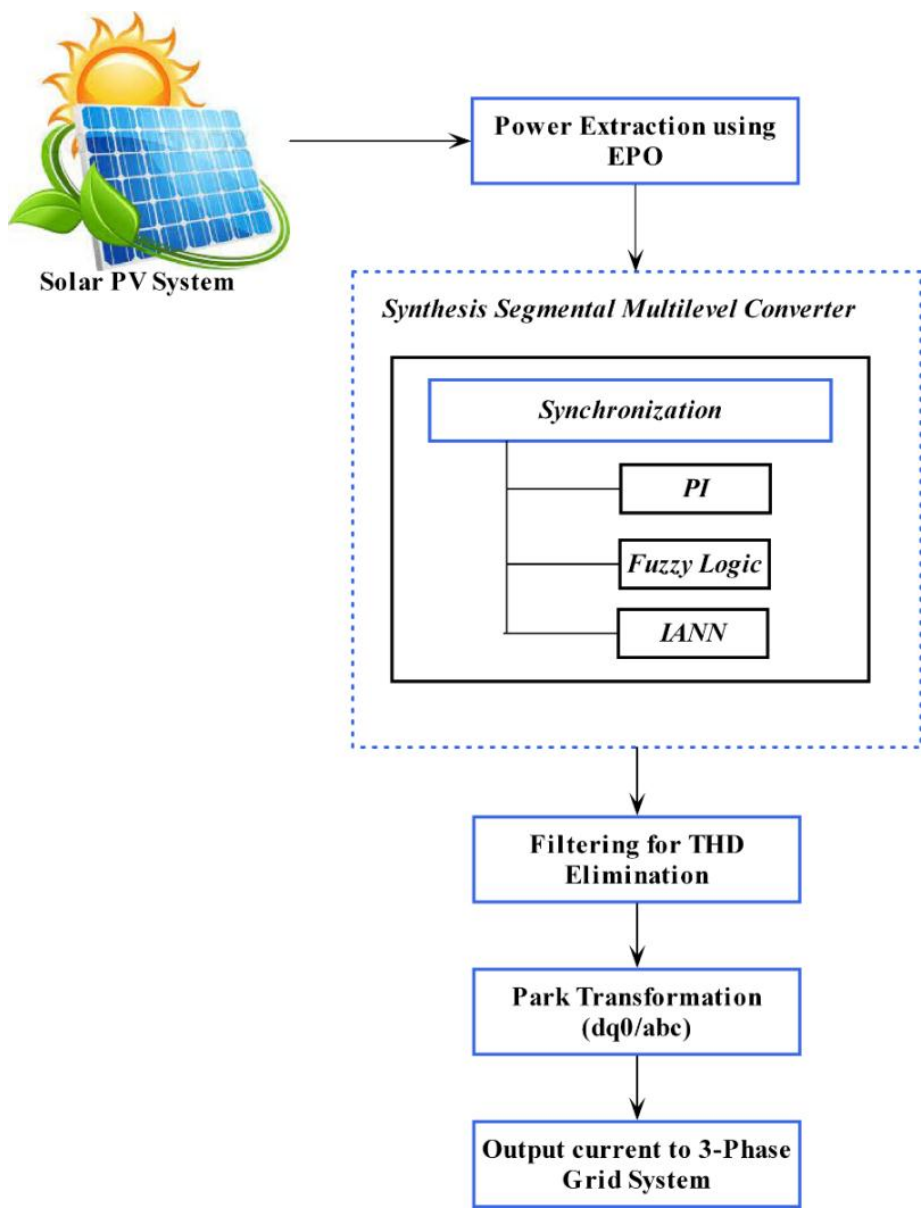

Fig 2. Overall flow of the proposed system

\subsection{Power Extraction}

At first, the maximum powers from the solar PV systems are extracted by using and Enhanced P\&O technique (EPO), which is one of the MPPT controlling mechanism. It is an extensively used controlling technique due to its easy implementation and limited parameters requirement. Moreover, it intends to find the maximum power based on the operations of perturbing and observing the power using PV modules. This technique estimates the power based on the values of voltage and current observed from the PV modules. The major benefits of using EPO method are fast response and improved accuracy rate. In addition to that, it reduces the oscillations by optimally selecting the sampling period and duty cycle. Here, the power extracting from the solar PV system is done by using the EPO method, where the current is generated as follows:

$I=I_{p h}-I_{D}-I_{s h}$

Where, $I$ indicates the output current, $I_{p h}$ denotes the PV current, $I_{D}$ represents the diode current, and $I_{s h}$ is the shunt current. Consequently, the PV current is generated based on the below equation: 


$$
I_{p h}=\frac{G}{G_{r e f}}\left(I_{s c, r e f}+\mu_{s c} \cdot \Delta T\right)
$$

Where, $\mathrm{G}$ is the irradiation in terms of Watt $/ \mathrm{m}^{2}, \mathrm{G}_{\mathrm{ref}}$ indicates the irradiation at STC, $\mathrm{I}_{\mathrm{sc}, \text { ref }}$ represents the reference short circuit current, $\mu_{\mathrm{sc}}$ indicates the temperature coefficient $(\mathrm{A} / \mathrm{k})$, and $\Delta \mathrm{T}$ is computed as follows:

$\Delta T=T-T_{r e f}$

Where, $\mathrm{T}$ is the temperature in terms of kelvin and $\mathrm{T}_{\mathrm{ref}}$ indicates the temperature at STC. The current flow through the diode $\left(I_{D}\right)$ is estimated by using the Shockley diode equation, which is illustrated as follows:

$I_{D}=I_{0}\left[\exp { }^{\left(\frac{V+I R s}{a}\right)}\right]$

$I=I_{p h}-I_{0}\left[\exp ^{\frac{V+I R_{S}}{a}}\right]-\left(\frac{V+I R_{S}}{R_{P}}\right)$

Where, $I_{0}$ is the reverse saturation current of the diode, $R_{s}$ represents the series resistance, $R_{p}$ indicates the parallel resistance, and $a$ is the modified ideality factor. The detailed working steps involved in the EPO based power extraction from solar PV systems are illustrated in Fig 3.

\subsection{Synthesis Segmental Multilevel Converter}

After extracting the power from the PV systems, the panel separation has been done, where the input is split into 6 different panels for three phases of R, Y and B. In this SSMC converter design, the reactive power compensation is mainly concentrated for improving system efficacy and reduced harmonics. Here, the synchronization process is carried out by using the incorporated methodologies of PI controller, Fuzzy Logic Controller (FLC), and Improved Artificial Neural Network (IANN). Due to the incorporation of IANN with the proposed multilevel converter, it efficiently performs error compensation, when compared to the conventional MMC technique. The block representations of SSMC design and the synchronization are depicted in Fig 4 and Fig 5. During the process of synchronization, the values of parameters such as voltage, magnitude and phase angle are maintained in a same level for improving system performance. Also, the better synchronization makes efficient control actions with the grid parameters. Then, the switching pulses can be generated accordingly with the use of IGBT switches. Moreover, the active power reference could be gradually increased for connecting the SSMC with the grid. In addition to that, a pre-charging resistor is utilized to charge all the sub-modules with respect to the PV panel voltage. 


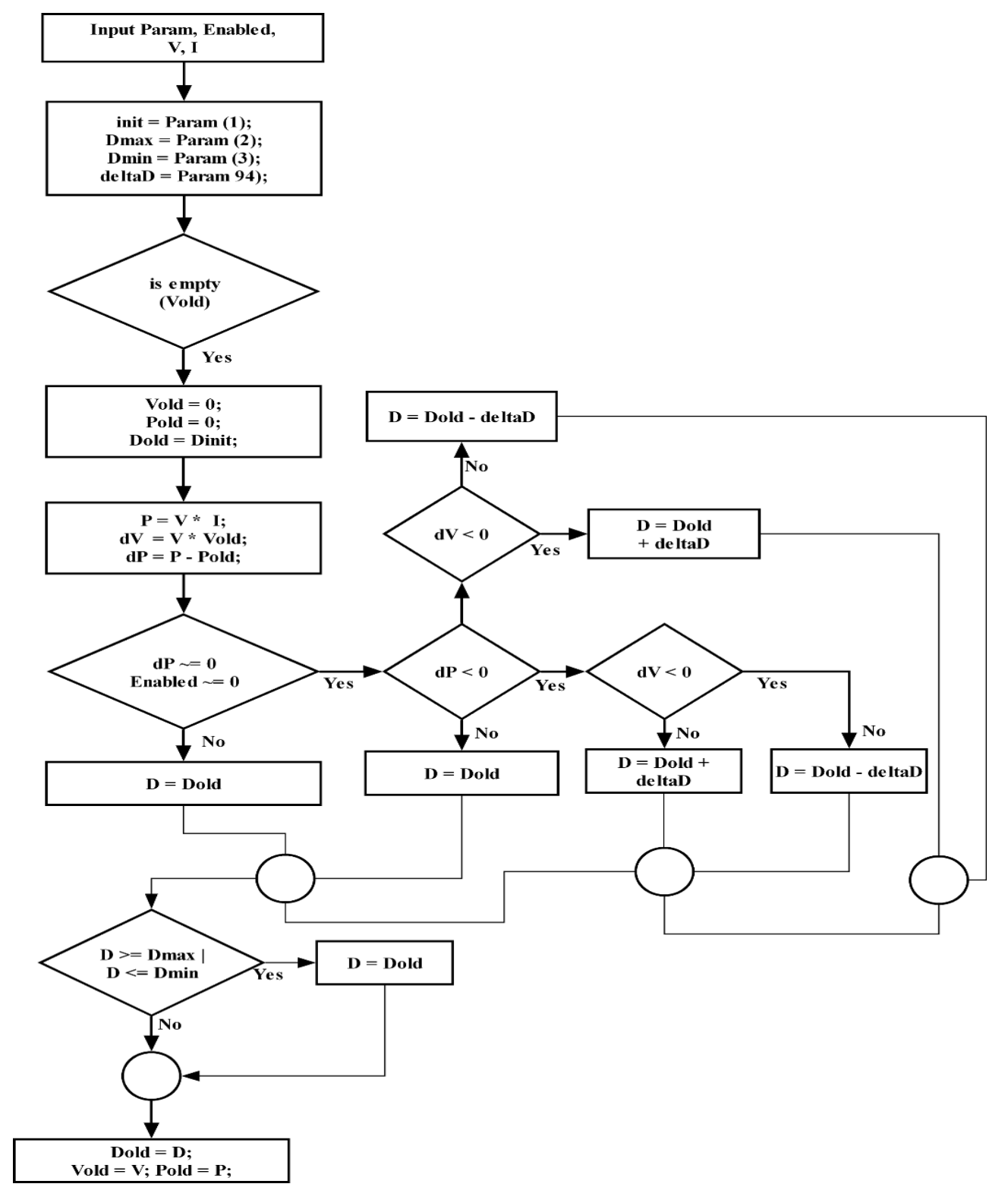

Fig 3. Model of EPO method 


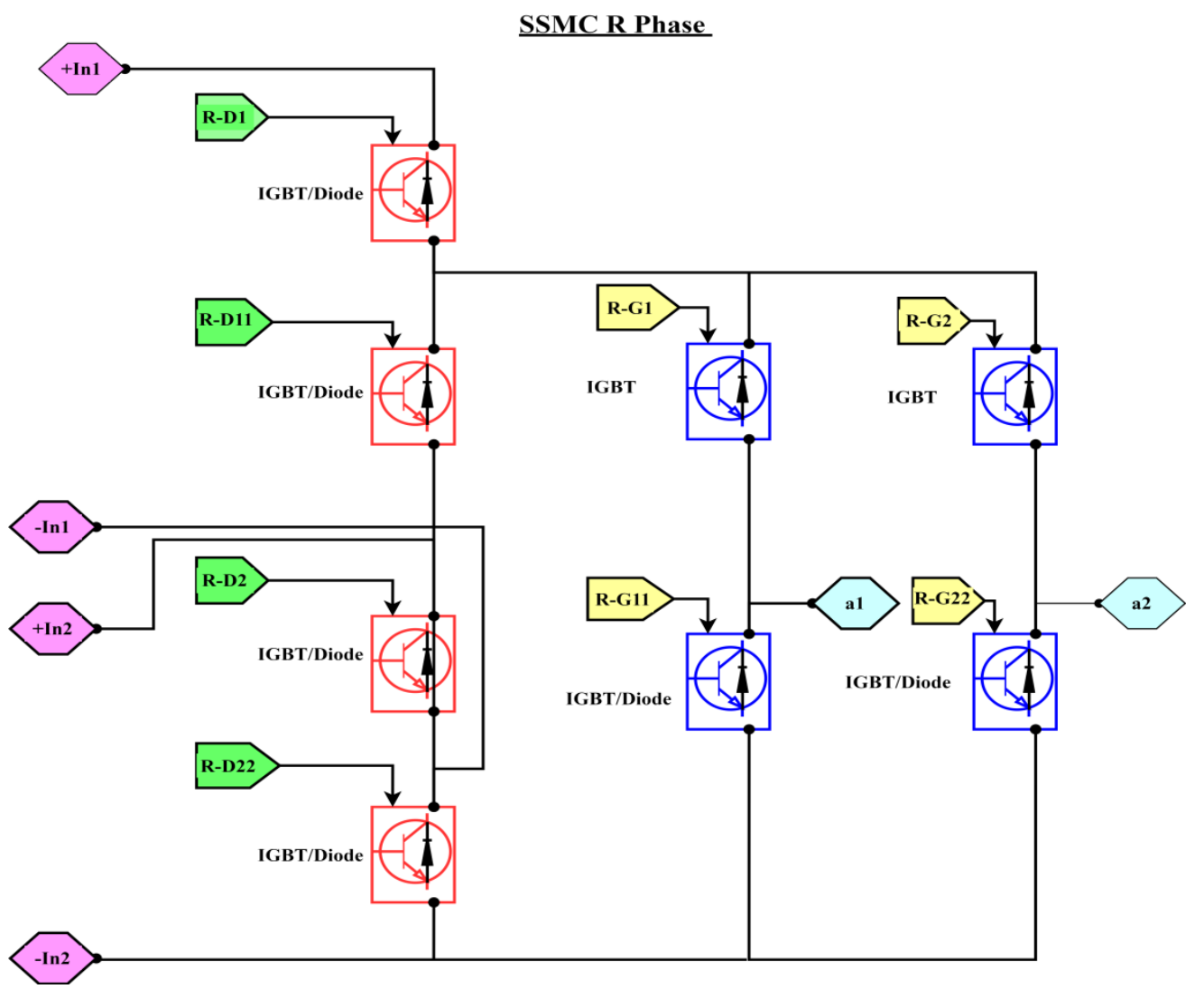

Fig 4. Converter design using SSMC

PI Based Grid Synchronization

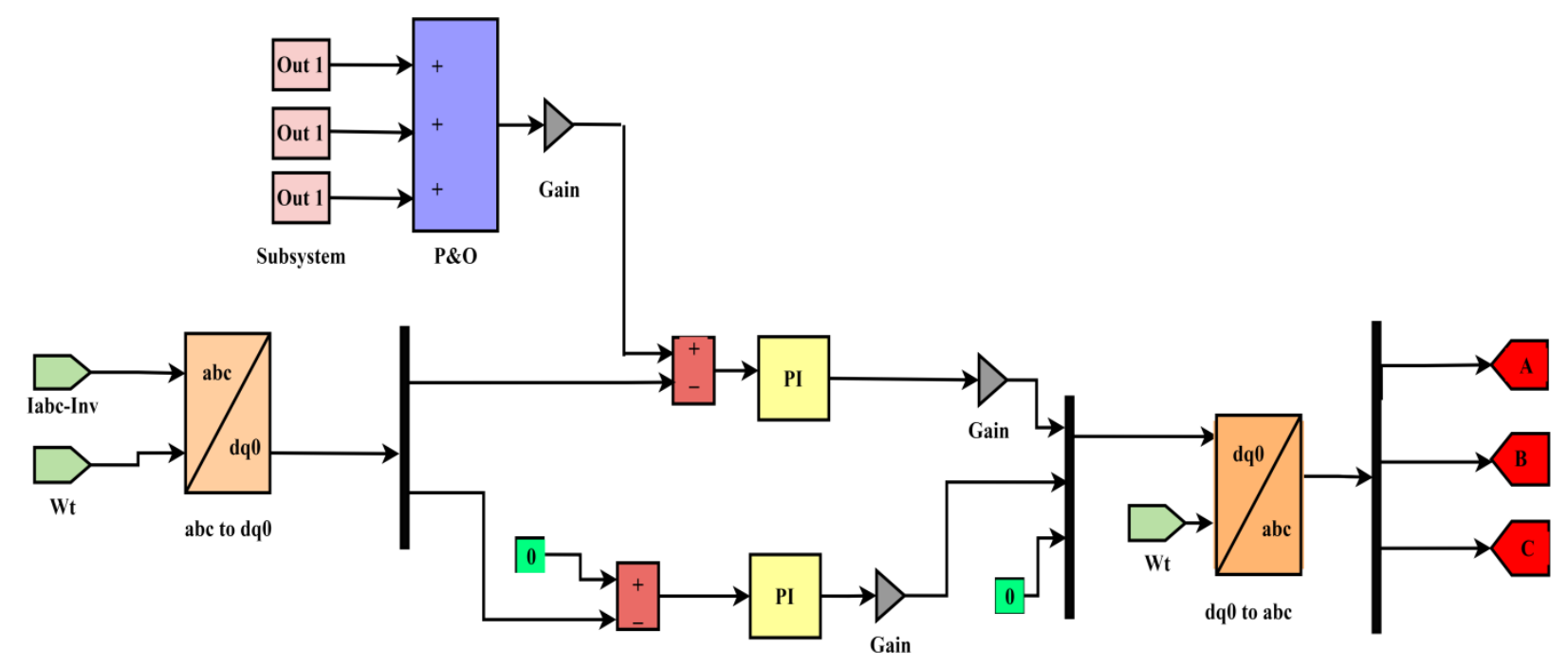

Fig 5. Grid synchronization 


\subsubsection{PI Controller}

The Proportional Integral (PI) controllers have been widely used for increasing the stability and dynamic response of the power distribution systems. It is mainly used to reduce the error value by finding the difference between the inverter output and the amount of power calculated to the grid. Moreover, it provides an optimal solution, so it is the suitable option for the three phase grid system. Also, this controller screens the voltage and current of the PV array for adjusting the duty cycle ratio.

\subsubsection{Fuzzy Logic Controller (FLC)}

The FLC is also an extensively used controlling technique, which requires both the input and output variables, based on these values, the controlling has been done. In this method, the discrete time error is estimated based on the difference between the output variable $y(k)$, and reference variable $r(k)$. Then, the current sample $e(k)$ and its change of error $\Delta e(k)$ are represented as follows:

$e(k)=r(k)-y(k)$

$\Delta e(k)=e(k)-e(k-10)$

Here, the controller is used to reduce the error in an efficient manner, which also improves the systems performance. Consequently, the fuzzy output has been generated based on the knowledge based rules. Then, the controller output of fuzzy logic is illustrated as follows:

$u(k+1)=u(k)+\Delta u(k)$

Where, $u(k+1)$ is the fuzzy controller output and $\Delta u(k)$ indicates the sample output. In which, the sampling time will be changed until reaching the steady state condition. Similar to that, the defuzzification can be performed to evaluate the original output of fuzzy controller. After that, the weighted mean value is calculated with respect to the membership function $\mu\left(u_{i}\right)$, which is shown in below:

$u=\frac{\sum_{i=1}^{k} u_{i} \times \mu\left(u_{i}\right)}{\sum_{i=1}^{k} \mu\left(\mu_{i}\right)}$

The major benefit of using this FLC controlling technique is, it produces the better output power under various solar irradiation levels.

\subsubsection{Improved Artificial Neural Network (IANN)}

Typically, the IANN based controlling technique offers the most appropriate solution for any complex systems, due to this reason, many controlling systems utilize this technique. This type of mechanism works like a black box model, which does not require the complete information about PV systems. Moreover, the maximum peak point is identified by generating the duty ratio between the layered architecture. In this algorithm, the feed forward current and PV voltage are considered as the input source, which are received by the input layer under varying temperature and radiation levels. The relation between the layers are estimated as follows: 
$h_{j}^{i}=\sum_{i=1}^{2} e_{j i} a_{i}+y_{j}^{1}, j=1 \sim 10$

Where, $e_{j i}$ defines the weighting function connected from the $i^{t h}$ input, $y_{j}^{1}$ is the bias of the hidden layer neurons. The output of the neurons are represented as follows;

$x_{j}^{1}=f_{1}\left(\sum_{i=1}^{2} e_{j i} a_{i}+y_{j}^{1}\right), f_{1}(x)=\operatorname{purelin}(a)=a$

The net input to the output layer is represented as follows:

$h_{k}^{2}=\sum_{i=2}^{10} e_{k j} x_{j}^{1}+y_{k}^{2}, k=1 \sim 4$

Where, $e_{k j}$ defines the weight on the connection from $j^{\text {th }}$ input and $y_{k}^{2}$ represents the bias for the hidden layer neurons. Then, $x_{k}^{2}$ indicates the networks output of interest, and its output is denoted as $b_{k}$, which are illustrated as follows:

$x_{k}^{2}=b_{k}=f_{2}\left(\sum_{j=1}^{10} e_{k j}+y_{k}^{1}\right), f_{2}(a)=\operatorname{purelin}(a)=a$

The structure of ANN technique with its working layers are shown in Fig 6, where the PV voltage and current are taken as the input by the input layer, then its processed at the hidden layer and the final outcome is produced by the output layer.

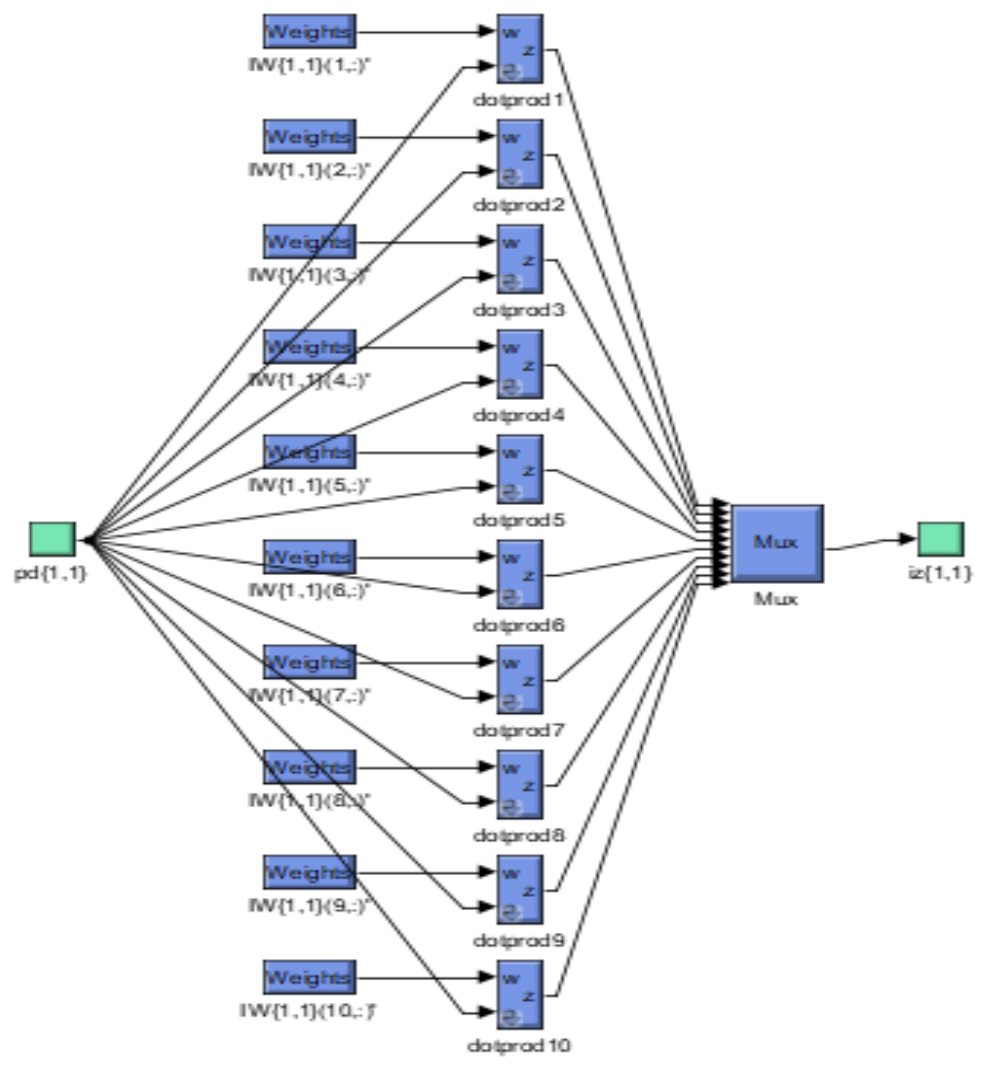

Fig 6. Structure of IANN 
In the proposed IANN, the gain parameters have been utilized to train the network model based on the error and input error values. Also, it predicts the optimal parameters of the PI controller with respect to the PQ factor differences. So, it offers the better results compared than the traditional ANN techniques.

\subsection{Filtering}

After synchronization, the $\mathrm{L}$ and $\mathrm{C}$ filtering technique is applied to reduce the harmonics in the power. The aim of using this filtering technique is to attain high performance and reduced power loss. Also, it provides related to $50 \mathrm{~Hz}$ frequency output power to the grid systems, which efficiently reduces the higher order harmonics. After removing the harmonics from the signal, it combines the output voltage to the grid system.

\subsection{Transformation}

After filtering, the Voltage Source Inverter (VSI) is used to change the DC input voltage to an AC output voltage. Then, the park transformation is applied to reduce the high volume of error, which makes the process of controlling as easily achievable. Also, it offers an accurate control to the signals for perfect voltage regulation. Typically, the dq0/abc transformation is represented based on the conversion from the three phase reference frame into a two phase reference frame, which is estimated as follows:

$$
\begin{aligned}
& {\left[\begin{array}{l}
X_{d} \\
X_{q} \\
X_{0}
\end{array}\right]=[T]\left[\begin{array}{l}
X_{a} \\
X_{b} \\
X_{C}
\end{array}\right]} \\
& {\left[\begin{array}{l}
y_{d} \\
y_{q} \\
y_{0}
\end{array}\right]=[T]\left[\begin{array}{l}
Y_{A} \\
Y_{B} \\
Y_{C}
\end{array}\right]} \\
& {[T]=\sqrt{\frac{2}{3}}\left[\begin{array}{ccc}
\sin \alpha & \sin \left(\alpha-\frac{2 \pi}{3}\right) & \sin \left(\alpha+\frac{2 \pi}{3}\right) \\
\cos \alpha & \cos \left(\alpha-\frac{2 \pi}{3}\right) & \cos \left(\alpha+\frac{2 \pi}{3}\right) \\
\frac{1}{\sqrt{2}} & \frac{1}{\sqrt{2}} & \frac{1}{\sqrt{2}}
\end{array}\right]}
\end{aligned}
$$

Where, $X_{d}, X_{q}$ are the grid voltage and current, and $y_{d}, y_{q}$ are the DC components of the inverter output. Finally, the converted signals are given to the three phase grid system with better reactive power compensation rate.

\section{Results and Discussion}

This section evaluates the simulation and analytical results of the proposed SSMC design based on various performance measures. Also, some of the existing controlling techniques have been compared with the proposed system for proving the efficiency. 


\subsection{Grid Voltage and Current}

Generally, the solar inverters are required to synchronize their frequency to the grid voltage and current. The SSMC output current can be controlled by the grid current in order to track the reference current. These values are mainly estimated to analyze the value of reactive power that is absorbed by the inverter. The required amount of voltage and current must be reduced to evade the unnecessary losses on the power system. Fig 7 shows the amount of grid voltage and current required by the proposed SSMC design.

\subsection{Inverter Voltage and Current}

Fig 8 shows the output inverter voltage and current of the proposed SSMC system. Naturally, the multilevel inverter has the ability to control the high voltage systems with reduced harmonics. Here, the VSI is utilized to convert the DC input voltage to AC output voltage. Then, its output voltage and current are illustrated to represent the efficacy of VSI in signal conversion.
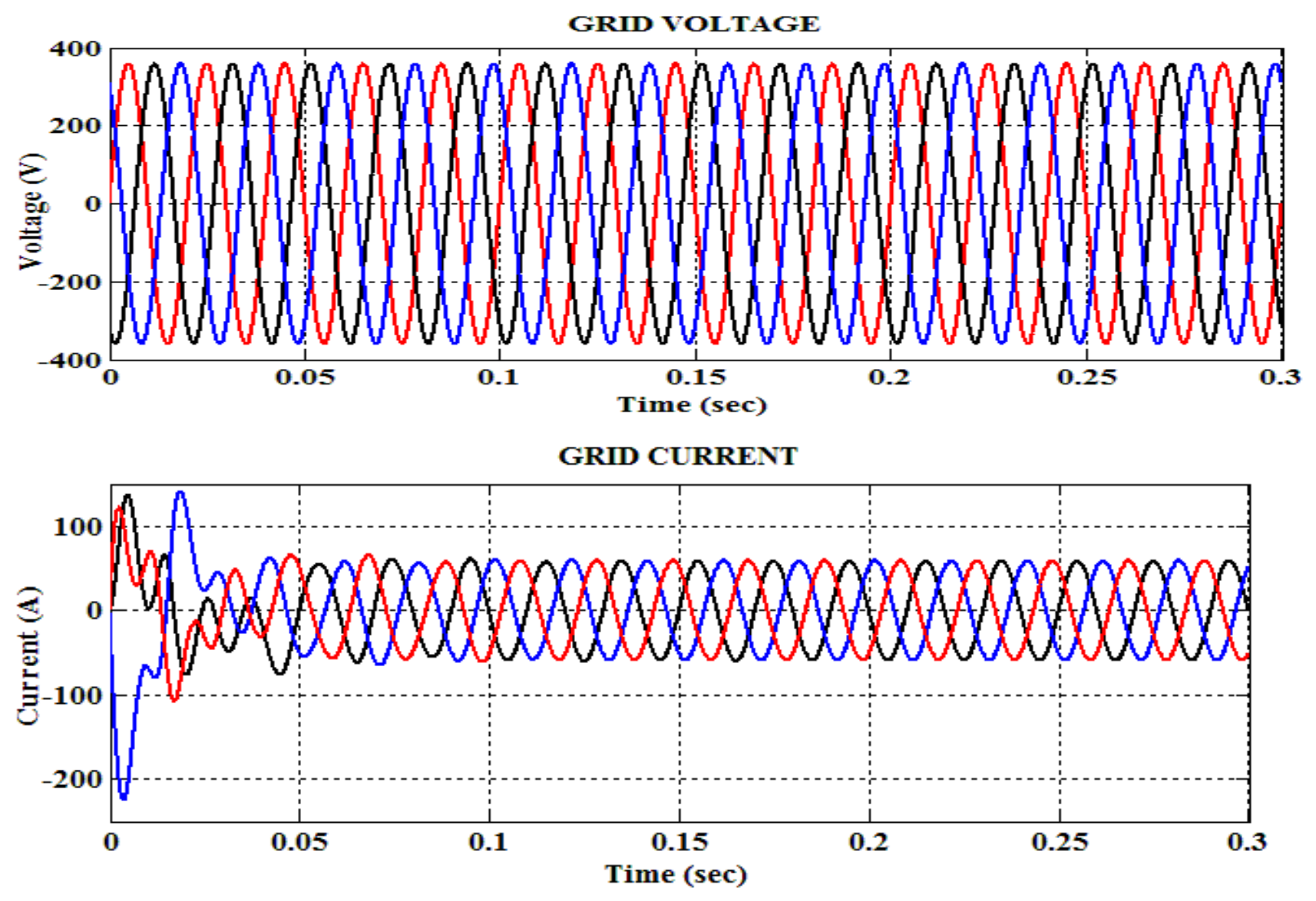

Fig 7. Grid voltage and current 

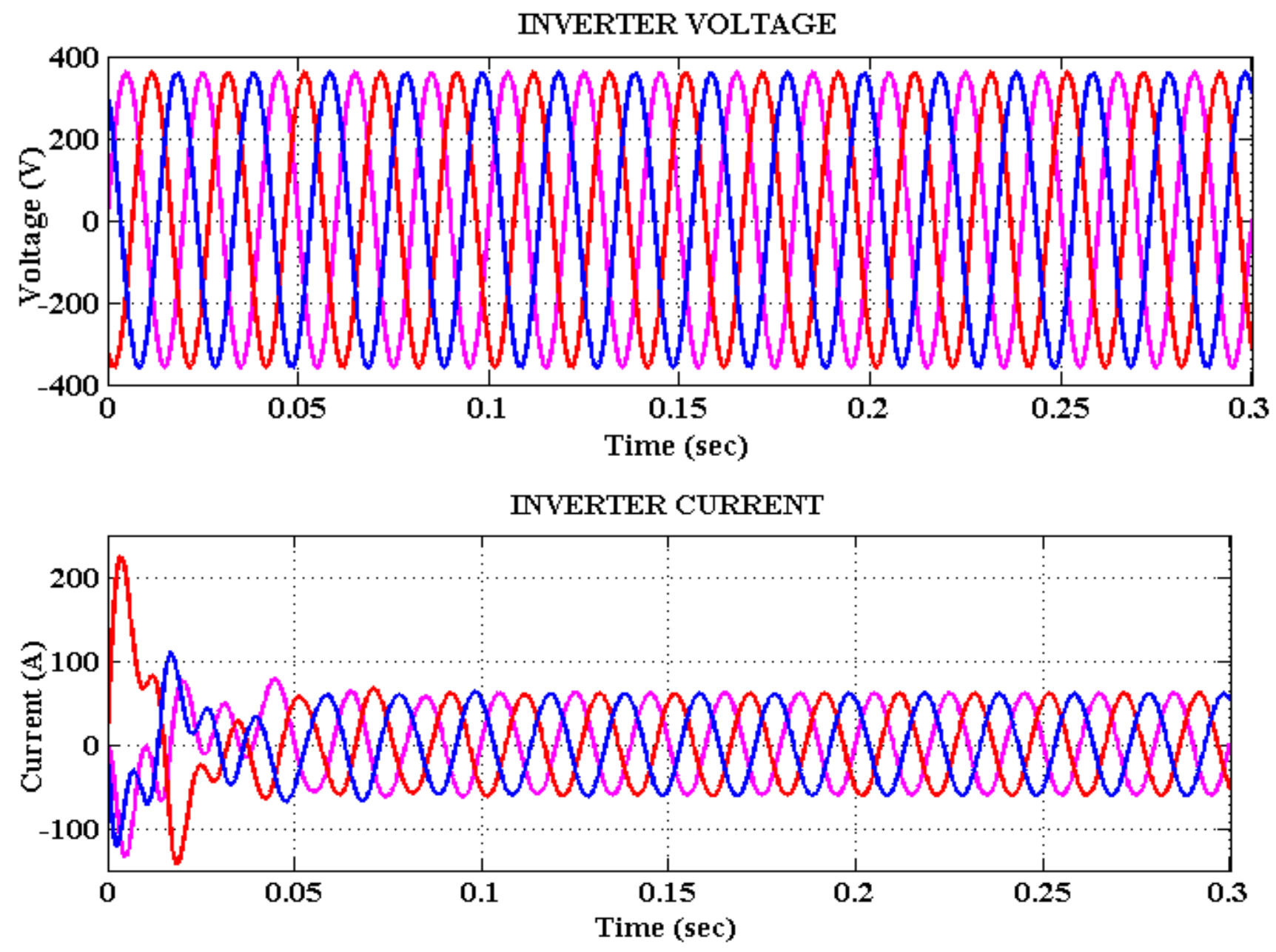

Fig 8. Inverter voltage and current

\subsection{Real and Reactive Power}

Fig 9 depicts the output real and reactive power of the proposed SSMC converter design. Due to proper synchronization with the grid system, the real and reactive power outputs are drawn efficiently. This result illustrated that the improvement of reactive power compensation in the three phase grid system using SSMC design. Similarly, the comparative analysis between the PI, FLC and IANN controlling techniques with respect to the real and reactive power generated from the PV source is illustrated in Fig 10. Then, the real and reactive power provided by the three phase source is shown in Fig 11. These results indicate that the IANN performs the other controlling techniques with better supply rates. 

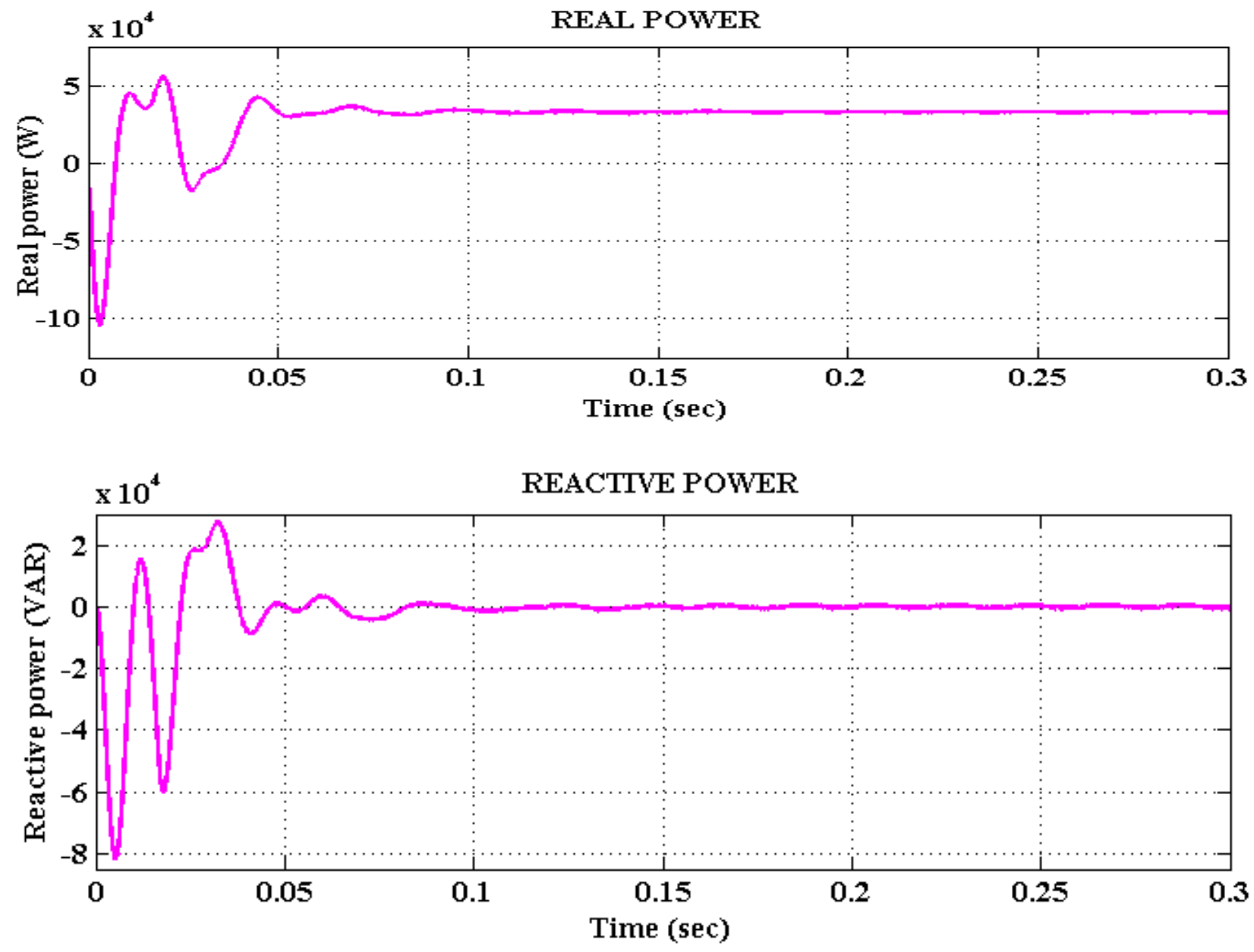

Fig 9. Real and reactive power

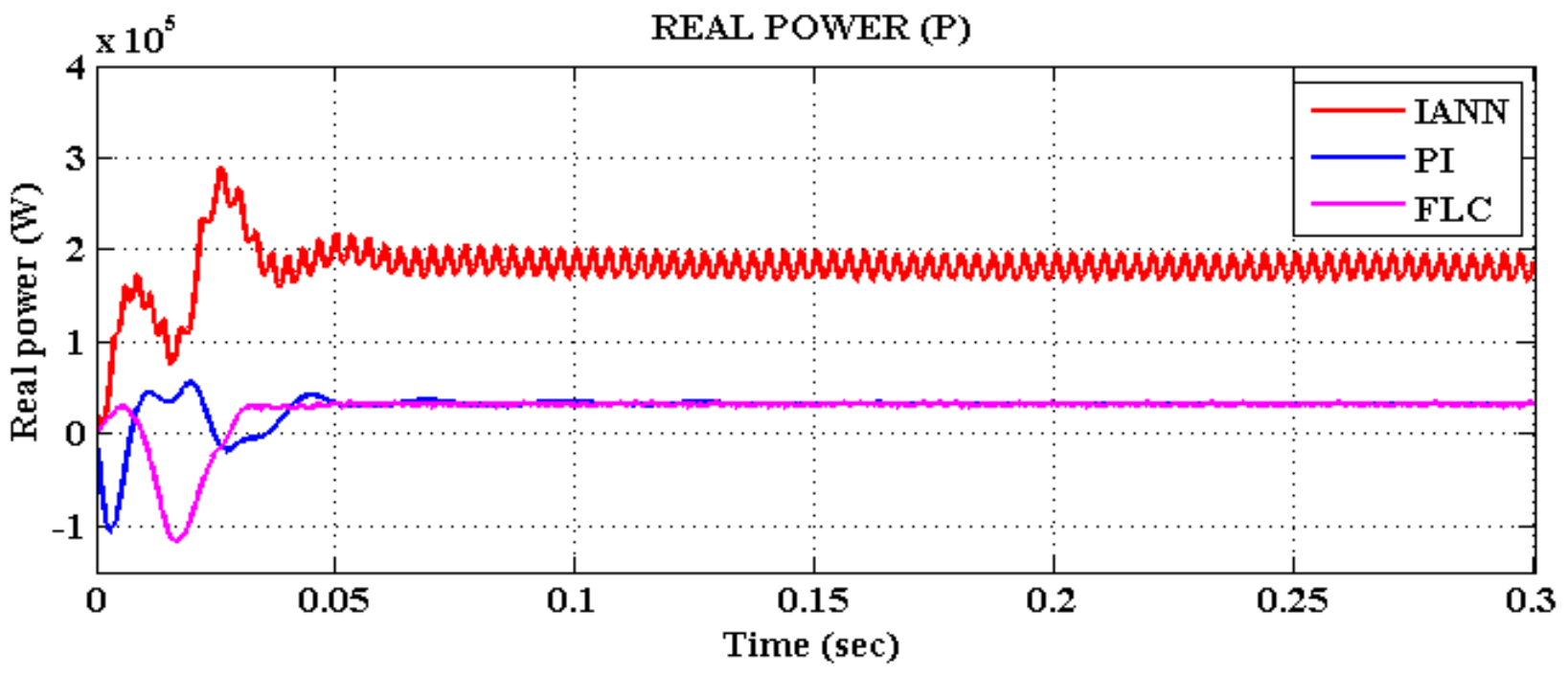




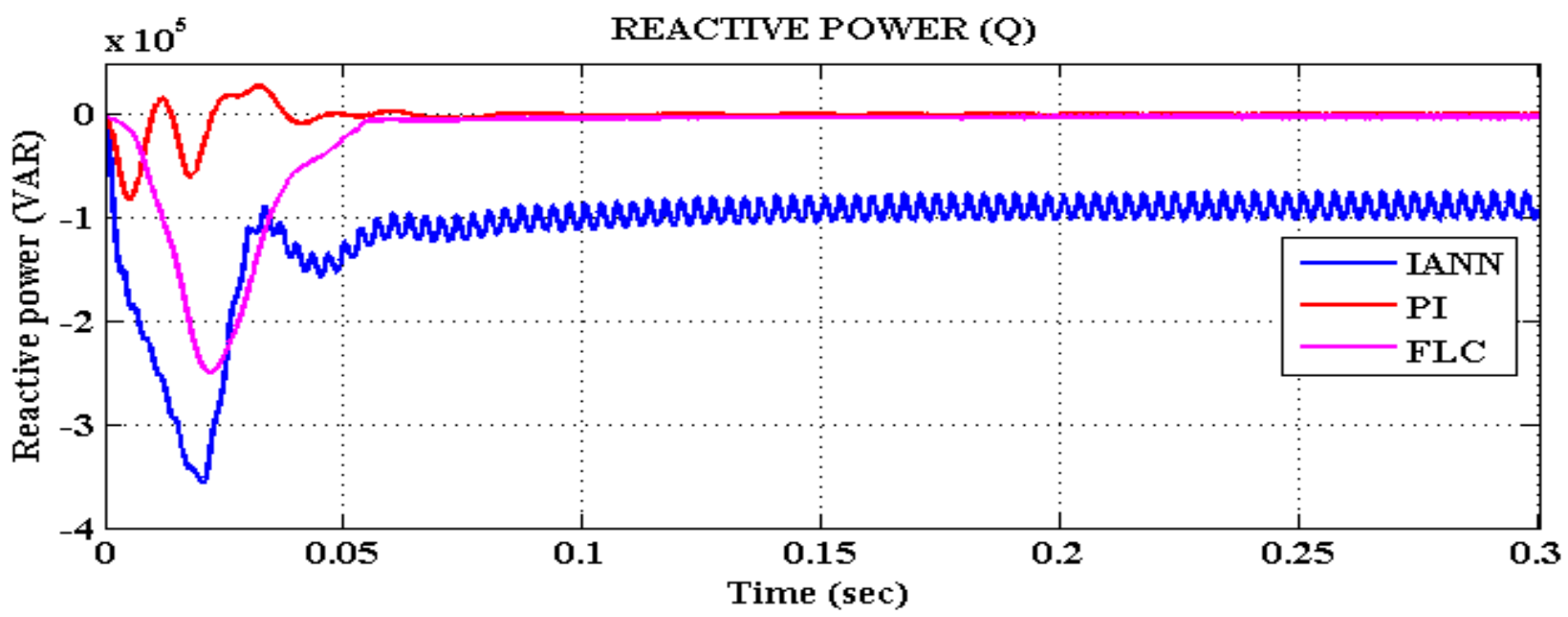

Fig 10. Real and reactive power supplied by PV system

REAL POWER (P)

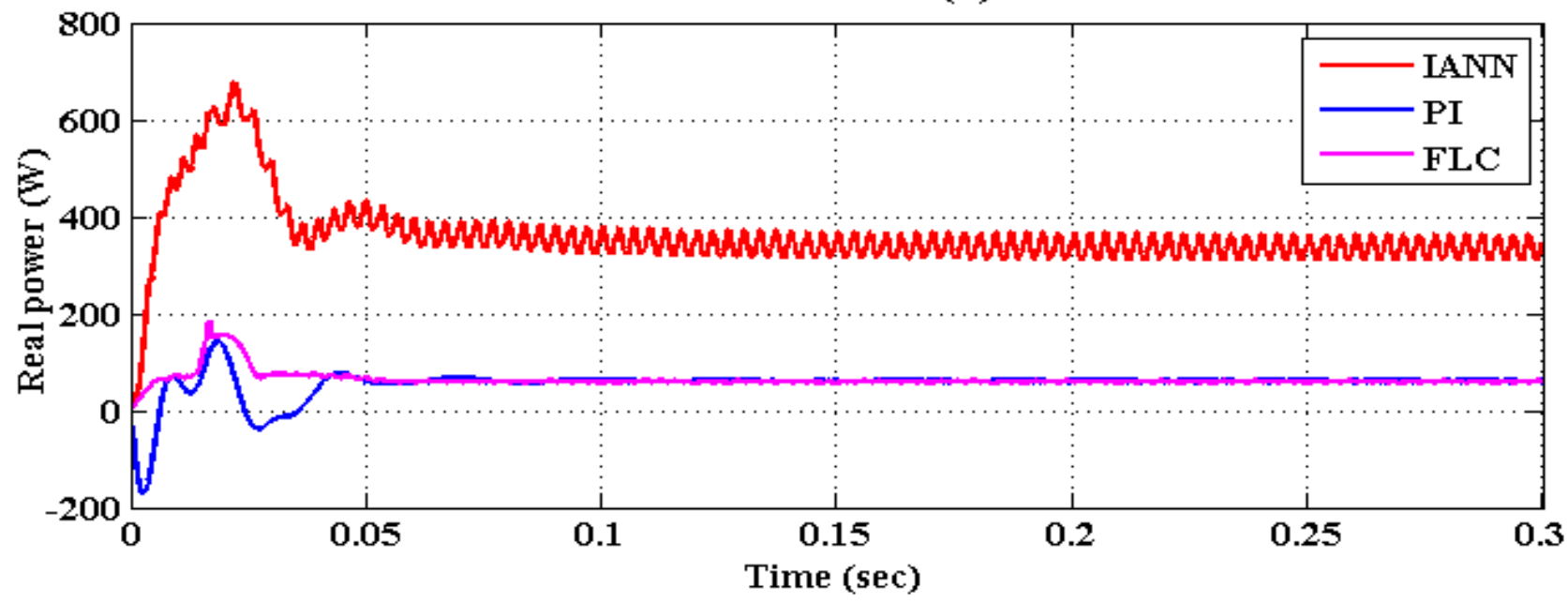

REACTTVE POWER (Q)

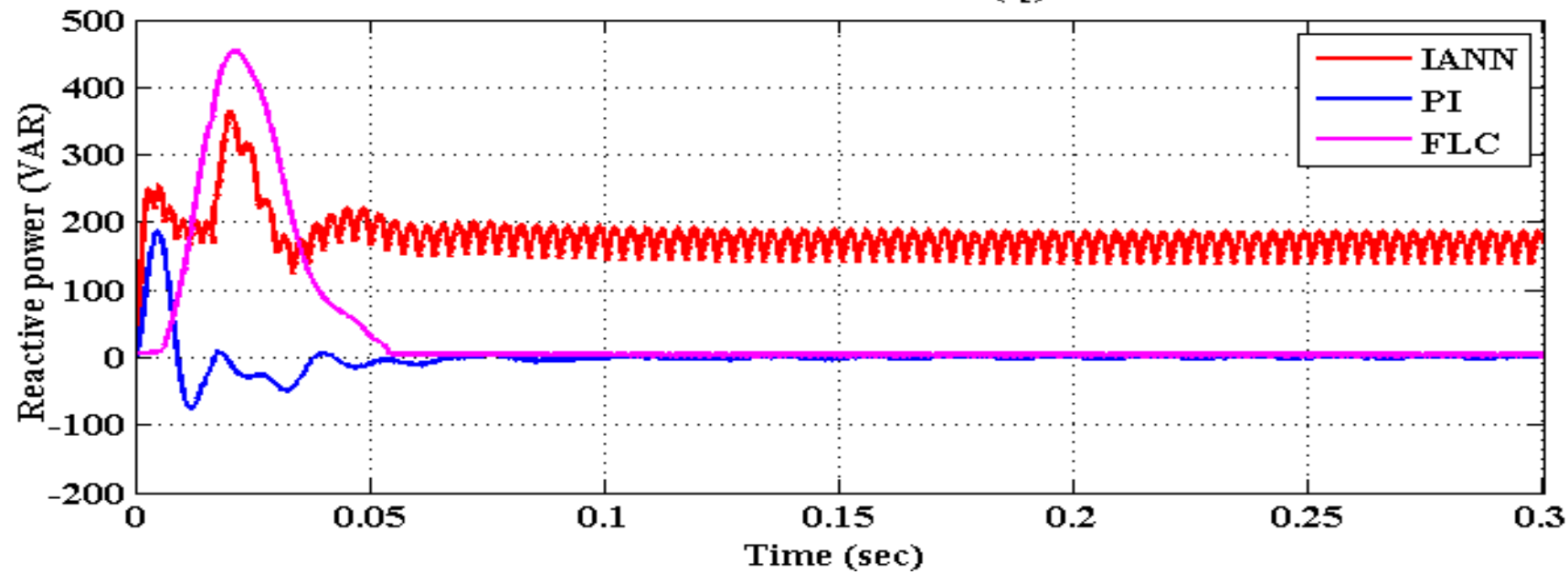

Fig 11. Real and reactive power provided by three phase source

Fig 12 depicts the dq axis of the grid system, where the d-axis and q-axis signals are represented separately. Fig 13 shows the reference current generated using MPPT, which is 
estimated based on the error value between the actual voltage, and MPP voltage. Based on the active and reactive power exchange in a grid system, the reference voltage can be adjusted with respect the maximum peak point.
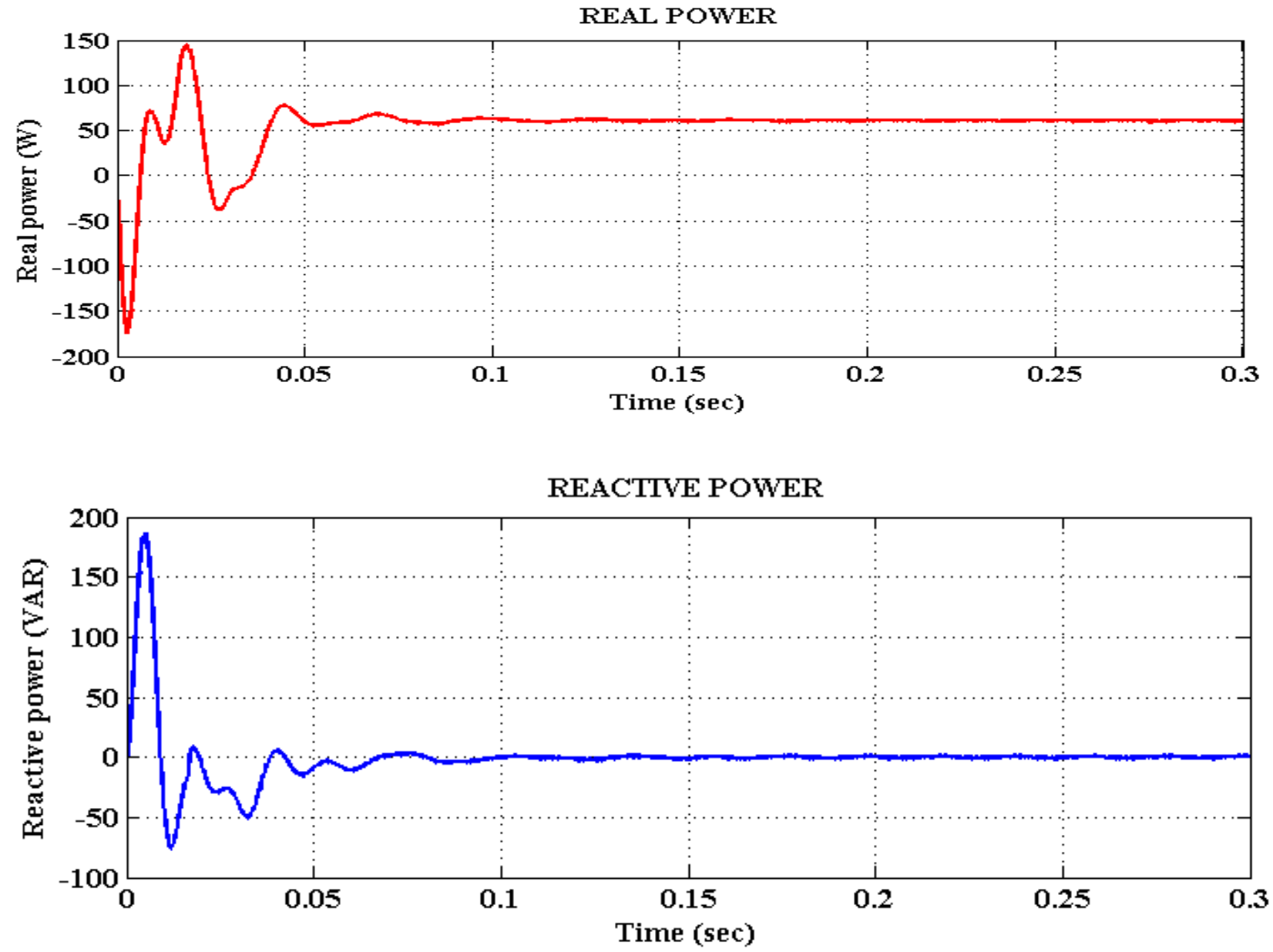

Fig 12. dq axis

Reference Current from MPPT

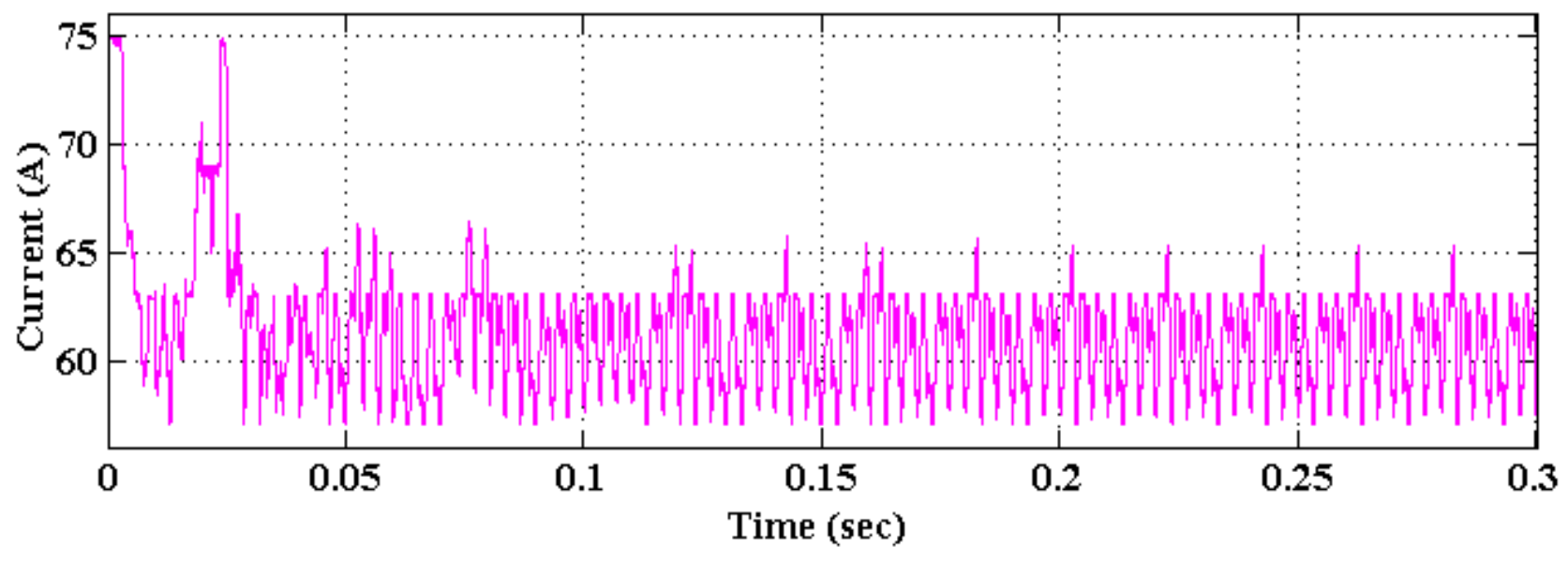

Fig 13. Reference current from MPPT 


\subsection{SSMC Output}

The output waveforms of SSMC, half bridge sub module, gate pulse and abc transformed signal are illustrated in Fig 14 to Fig 17. The half bridge sub-module is one of the essential component of SSMC. These simulation results indicate that the SSMC offers the better power outputs by efficiently performing the reactive power compensation based on the synchronization process.

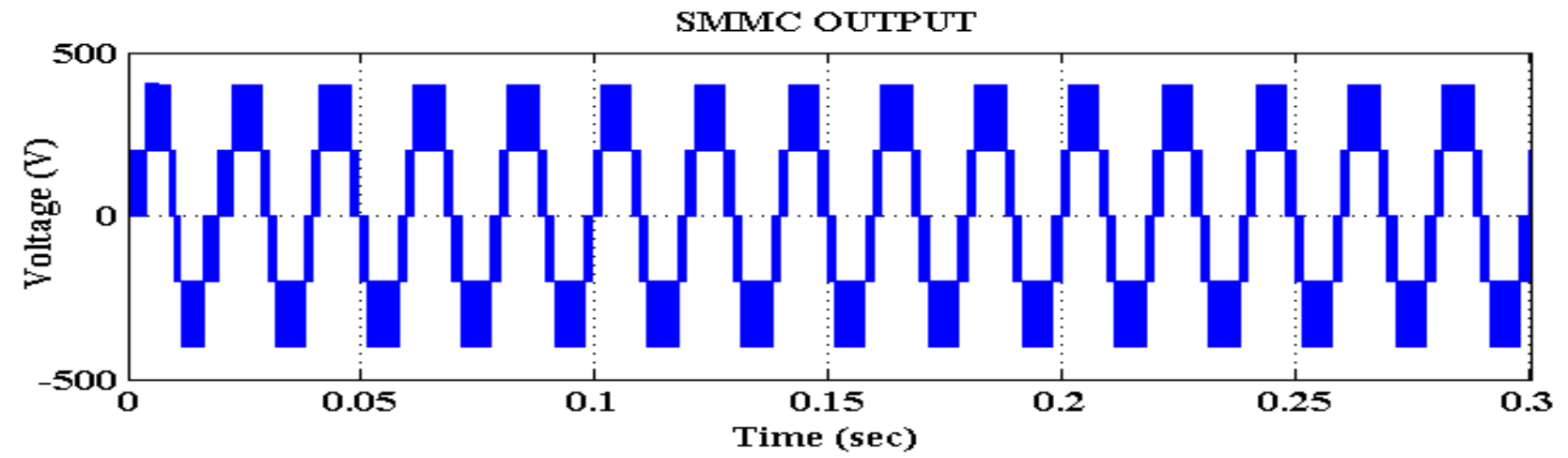

Fig 14. SSMC Output

H-BRWGE

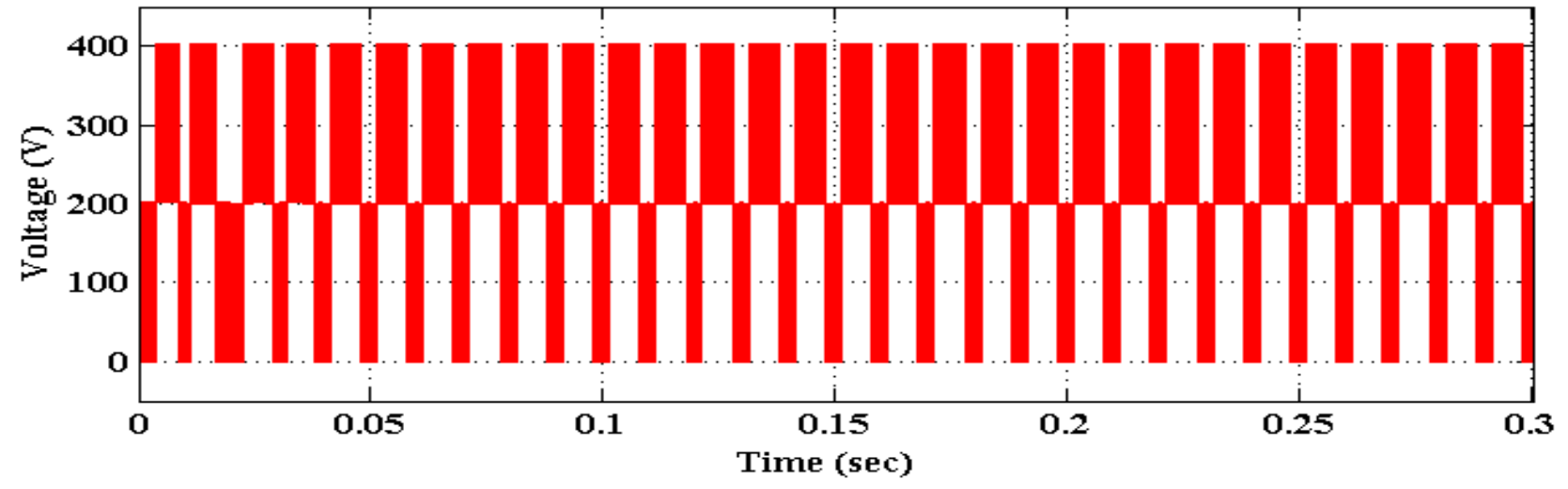

Fig 15. Half bridge sub module

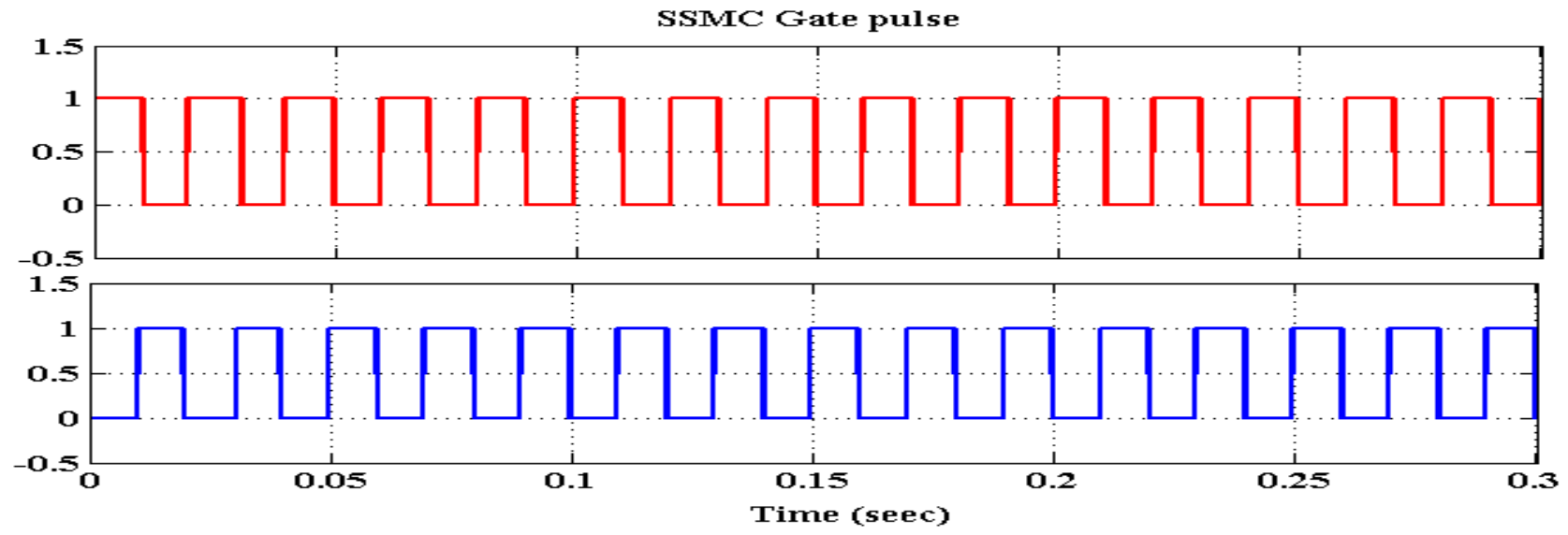

Fig 16. SSMC Gate pulse 

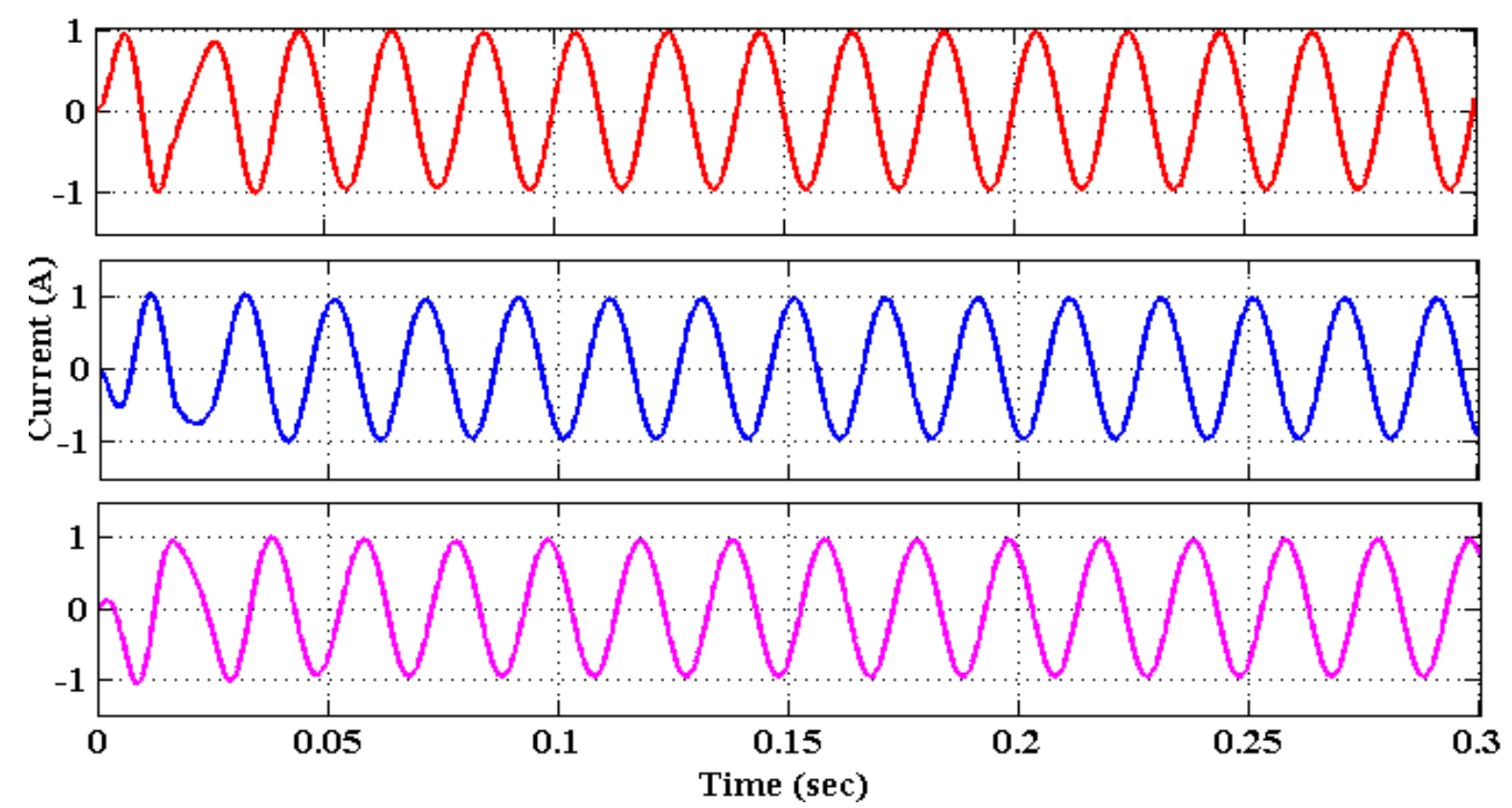

Fig 17. abc transformed output signal

Table 1 and Table 2 compares the settling time, peak time and rise time of various controlling technique such as PI, FLC and IANN. Typically, the settling time of the controller can be evaluated based on the magnitude of the frequency disturbance. Then, the peak time is defined as the time required to estimate the peak point of the grid system. From this analysis, it is evident that the IANN provides the reduced time consumption compared than the other controlling techniques.

Table 1. Settling time and Peak time of various controlling techniques

\begin{tabular}{|c|c|c|c|c|}
\hline $\begin{array}{c}\text { Controlling } \\
\text { Technique }\end{array}$ & \multicolumn{2}{|c|}{$\begin{array}{c}\text { Settling Time }\left(\mathrm{t}_{\mathrm{s}}\right) \\
(\mathrm{sec})\end{array}$} & \multicolumn{2}{c|}{$\begin{array}{c}\text { Peak Time }\left(\mathrm{t}_{\mathrm{p}}\right) \\
(\mathrm{sec})\end{array}$} \\
\cline { 2 - 5 } & $\mathrm{P}$ & $\mathrm{Q}$ & $\mathrm{P}$ & $\mathrm{Q}$ \\
\hline PI & 0.075 & 0.090 & 0.018 & 0.025 \\
\hline FLC & 0.055 & 0.059 & 0.025 & 0.027 \\
\hline IANN & 0.044 & 0.055 & 0.017 & 0.021 \\
\hline
\end{tabular}

Table 2. Rise time and Supply of various controlling techniques

\begin{tabular}{|c|c|c|c|c|}
\hline \multirow{2}{*}{$\begin{array}{c}\text { Controlling } \\
\text { Technique }\end{array}$} & \multicolumn{2}{|c|}{$\begin{array}{c}\text { Rise Time }\left(\mathrm{t}_{\mathrm{r}}\right) \\
(\mathrm{ms})\end{array}$} & \multicolumn{2}{c|}{$\begin{array}{c}\text { Supply power } \\
(\mathrm{W})\end{array}$} \\
\cline { 2 - 5 } & $\mathrm{P}$ & $\mathrm{Q}$ & $\mathrm{P}$ & $\mathrm{Q}$ \\
\hline PI & 6.274 & 9.925 & 75 & 10 \\
\hline FLC & 4.154 & 5.327 & 75 & 10 \\
\hline IANN & 2.386 & 2.831 & 375 & 175 \\
\hline
\end{tabular}


Table 3 shows the Total Harmonics Distortion (THD) analysis of various controlling techniques. Here, the THD analysis is mainly conducted to evaluate the overall efficiency of the proposed converter system. In this work, the LC based filtering technique is applied to reduce the high level harmonics present in the signal, which helps to obtain the low THD rate in an efficient manner. Then, the THD values of the phase voltage and current are estimated using FLC and IANN are 1.21 and 1.16 respectively. From the evaluation, it is proved that the IANN efficiently reduces the harmonics present in the output signal based on synchronization.

Table 3. THD analysis

\begin{tabular}{|c|c|}
\hline Controlling Technique & THD (\%) \\
\hline PI & 1.40 \\
\hline FLC & 1.21 \\
\hline IANN & 1.16 \\
\hline
\end{tabular}

Fig 18 depicts the THD analysis of the PI, FLC, and IANN controlling techniques with respect to varying frequencies $(\mathrm{Hz})$ and fundamental magnitude $(\%)$. In which, the THD is reduced to $1.40 \%$ by the PI controller, $1.21 \%$ by the FLC controller, and $1.16 \%$ by the IANN controller. These results proved that the THD value is minimized to a low rate by applying these controlling techniques, which efficiently improves the overall performance of the three phase grid system.

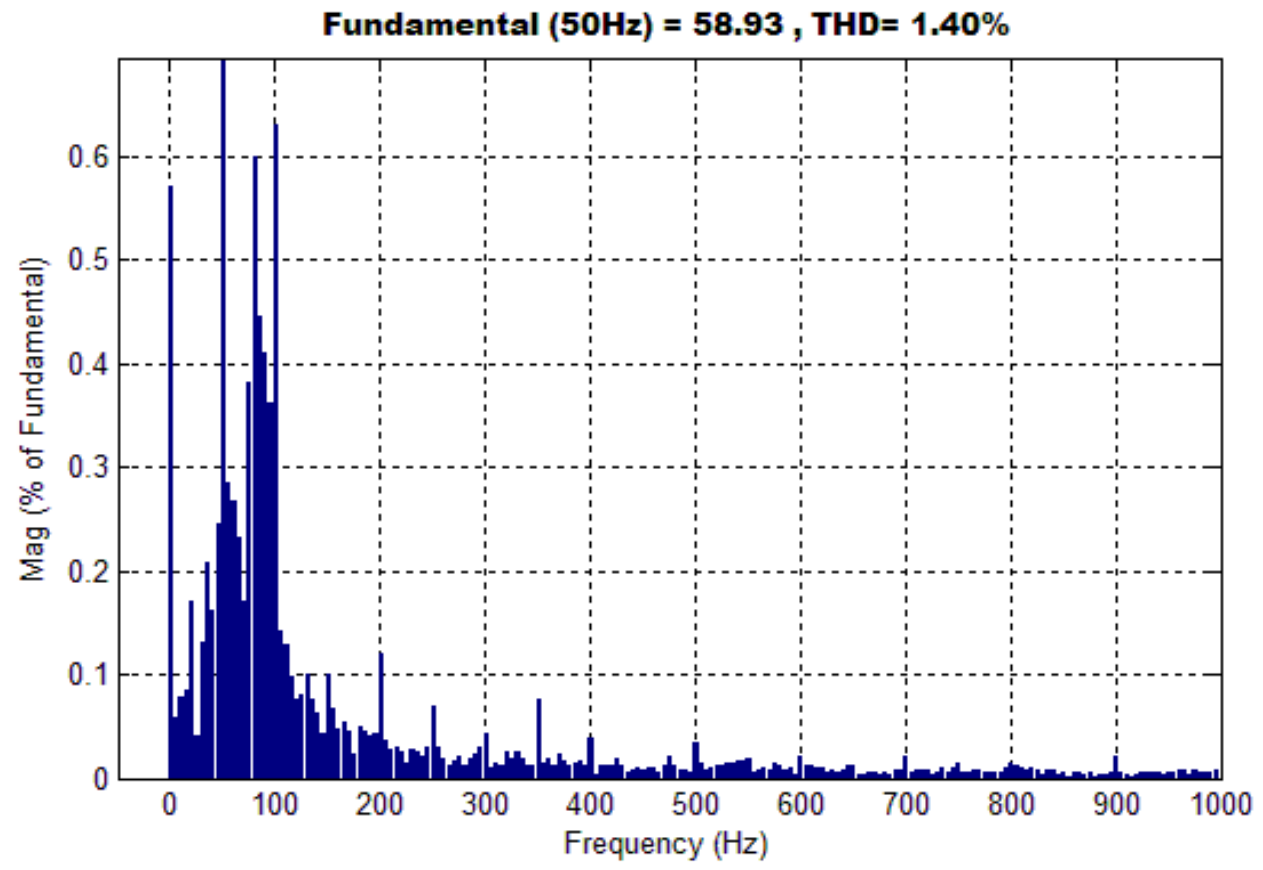

Fig 18 (a). THD analysis of PI controller 


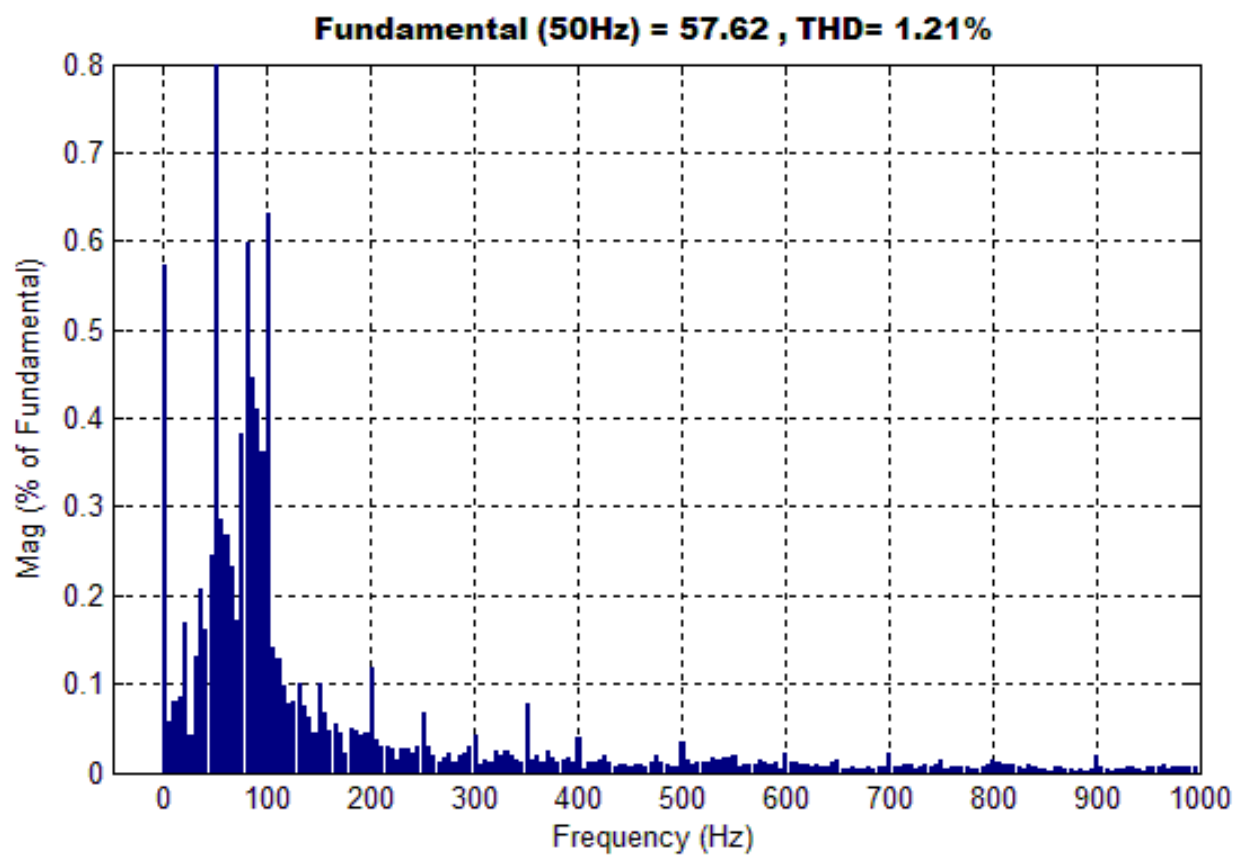

Fig 18(b). THD analysis of FLC controller

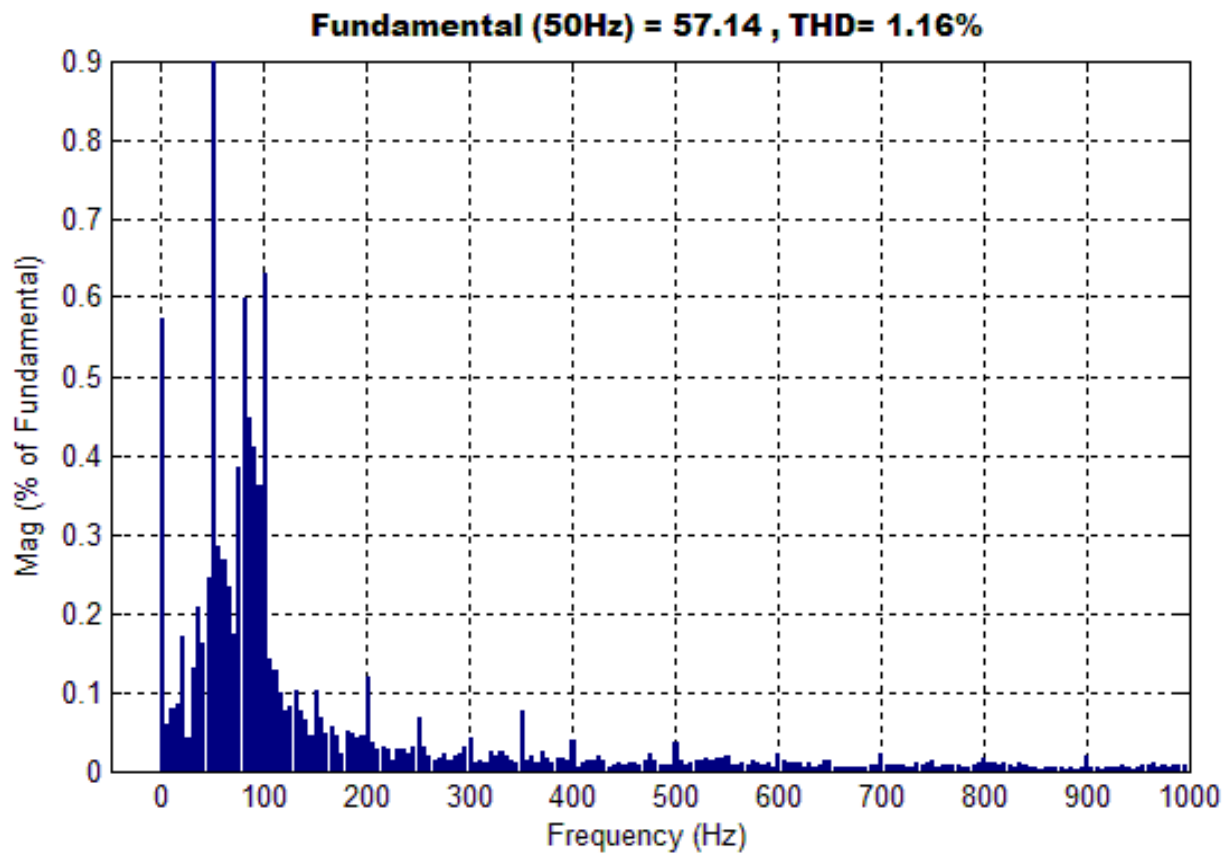

Fig 18(c). THD analysis of IANN controller 


\section{Conclusion}

This paper developed a new SSMC converter methodology for an efficient reactive power compensation in a three phase grid systems. The main aim focused on this work is to attain a significant performance in power systems by using a synchronization based controlling mechanism. The major stages in this paper are power extraction, converter design, filtering and transformation. Initially, the maximum power extraction from the solar PV systems is done by the use of EPO method. Then, the SSMC technique is employed to compensate the reactive power based on the synchronization process. In which, an integrated controlling techniques such as PI, FLC and IANN are utilized to maintain the voltage, phase angle and magnitude values in a same level. Then, the LC filtering technique is applied to reduce the harmonics present in the output signal of the converter. After that, the Park transformation is employed to reduce the high volume of error in the filtered signal. Here, the dq0/abc transformation is applied to convert the three phase output voltage, which is fed to the three phase grid system. The major advantages of this work are improved system stability, better performance rate in reactive power compensation, and reduced loss. In order to prove the efficiency of the proposed technique, an extensive simulation results have been validated by using various performance measures. The comparative results stated that the proposed SSMC provides the better performance outcome, when compared to the existing techniques.

In future, this work can be extended by applying this controlling strategy to a real time application environment.

Acknowledgements The authors are also thankful to the institute of Alagappa Chettiar Government College of Engineering and Technology, Karaikudi, Tamilnadu, India for providing all support to complete this research work.

\section{Declarations}

Ethical statement Articles do not rely on clinical trials. Human and animal participants All submitted manuscripts containing research which does not involve human participants and/or animal experimentation.

Funding This research received no external funding.

Conflict of interest The authors declare no conflict of interest. The funders had no role in the design of the study; in the collection, analyses, or interpretation of data; in the writing of the manuscript, or in the decision to publish the results.

Informed Consent Statement: Not applicable.

Author Contributions Conceptualization, R.N.; data curation, R.N. and S.V.; formal analysis, R.N. and S.V.; project administration R.N. and S.V.; investigation, R.N. and S.V.; methodology, R.N. and S.V.; software, R.N.; supervision, S.V.; writing-original draft, R.N. and S.V.; 
writing - review \& editing, R.N. and S.V. All authors have read and agreed to the published version of the manuscript.

\section{References}

Yang B (2019) Dynamic leader based collective intelligence for maximum power point tracking of PV systems affected by partial shading condition. Energy Conversion and Management 179: 286-303.

Shen (2017) Photovoltaic supplied grid-connected modular multilevel converter with active power injection and reactive power compensation capability. Paper presented at the IECON 2017-43rd Annual Conference of the IEEE Industrial Electronics Society.

Gandhi O (2017) Competitiveness of reactive power compensation using PV inverter in distribution system.Paper presented at the 2017 IEEE PES innovative smart grid technologies conference Europe (ISGT-Europe).

Joshi P and S Arora (2017) Maximum power point tracking methodologies for solar PV systems-A review. Renewable and Sustainable Energy Reviews 70:1154-1177.

Aktas A (2018). Dynamic energy management for photovoltaic power system including hybrid energy storage in smart grid applications. Energy 162:72-82.

Elserougi A, S Ahmed, and A Massoud (2016) Operation of three-phase modular multilevel converter (MMC) with reduced number of arms. IEEE International Conference on Industrial Technology (ICIT).

Tellez AA (2018) Optimal reactive power compensation in electrical distribution systems with distributed resources. Review. Heliyon 4(8):e00746

Mohamed MA, AAZ Diab, and H Rezk (2019) Partial shading mitigation of PV systems via different meta-heuristic techniques. Renewable energy 130:1159-1175.

Verma A and B Singh (2020) Multimode Operation of Solar PV Array, Grid, Battery and Diesel Generator Set Based EV Charging Station. IEEE Transactions on Industry Applications 56(5):5330-5339.

Nemet GF (2017) Characteristics of low-priced solar PV systems in the US. Applied Energy 187:501-513.

Ozbay H, S. Oncü, and M. Kesler (2017) SMC-DPC based active and reactive power control of grid-tied three phase inverter for PV systems. International Journal of Hydrogen Energy 42(28):17713-17722.

Zhang X (2018) Multilevel inverters for grid-connected photovoltaic applications: examining emerging trends. IEEE Power Electronics Magazine 5(4):32-41.

Gandhi O (2018) Analytical approach to reactive power dispatch and energy arbitrage in distribution systems with DERs. IEEE Transactions on Power Systems 33(6):6522-6533.

Mahfuz-Ur-Rahman A (2018) A novel active neutral point clamped multilevel converter with an advanced switching technique for grid integration of solar photovoltaic systems. IEEE Industry Applications Society Annual Meeting (IAS).

Kurtoğlu M (2019) Recent contributions and future prospects of the modular multilevel converters: A comprehensive review. International Transactions on Electrical Energy Systems 29(3):e2763.

Kraiczy M., T Stetz, and M Braun (2017) Parallel operation of transformers with on load tap changer and photovoltaic systems with reactive power control. IEEE Transactions on Smart Grid 9(6):6419-6428. 
Gong R., Xue B, Liu J \& Zhang X (2021) Power balance modulation strategy for hybrid cascaded H-bridge multi-level inverter. Electr. Eng.

Kolhe M L and M Rasul (2020) 3-Phase grid-connected building integrated photovoltaic system with reactive power control capability. Renewable Energy 154:1065-1075.

Santhoshi BK, Mohanasundaram K \& Kumar LA (2021) ANN-based dynamic control and energy management of inverter and battery in a grid-tied hybrid renewable power system fed through switched Z-source converter. Electr. Eng 103(5):2285-2301.

$\mathrm{Li}, \mathrm{H}$ (2017) Research on inverter integrated reactive power control strategy in the gridconnected PV systems. Energies 10(7):912.

Basu TS and S Maiti (2019) A hybrid modular multilevel converter for solar power integration. IEEE Transactions on Industry Applications 55(5):5166-5177.

Dutta S and K Chatterjee (2017) A buck and boost based grid connected PV inverter maximizing power yield from two PV arrays in mismatched environmental conditions. IEEE Transactions on Industrial Electronics 65(7):5561-5571.

Liu Z (2019) A power distribution control strategy between energy storage elements and capacitors for cascaded multilevel inverter with hybrid energy sources. IEEE Access 7: $16880-16891$.

Libo W, Z Zhengming and L Jianzheng (2007) A single-stage three-phase grid-connected photovoltaic system with modified MPPT method and reactive power compensation. IEEE Transactions on Energy Conversion 22(4):881-886.

Altawallbeh A, N Meskin, and A Massoud (2019) A Switching-Gain Controller for GridConnected MMC Complying with Voltage Ride-Through Requirements. IEEE 2nd International Conference on Smart Grid and Renewable Energy (SGRE).

Prasad V, P Jayasree, and V Sruthy (2018) Active power sharing and reactive power compensation in a grid-tied photovoltaic system. Materials Today: Proceedings,. 5(1): 1537-1544.

Yang R (2020) An LCC-MMC hybrid cascaded inverter applicable for UHVDC power overhead line transmission and dynamic reactive power self-compensation. Energy Reports 6:943952.

Mukundan CN (2020) Binary hybrid multilevel inverter-based grid integrated solar energy conversion system with damped SOGI control. IEEE Access 8:37214-37228.

Busarello TDC (2017) Three-phase battery storage system with transformerless cascaded multilevel inverter for distribution grid applications. IET Renewable Power Generation 11(6):742-749.

Muneer V and A Bhattacharya (2018) Cascaded H bridge multi level inverter based unified power quality conditioner.IEEE 8th Power India International Conference (PIICON).

Ramya G, V Ganapathy and P Suresh (2019) Comprehensive analysis of interleaved boost converter with simplified H-bridge multilevel inverter based static synchronous compensator system. Electric Power Systems Research 176:105936.

Mantilla MA, JF Petit and G Ordóñez (2021) Control of multi-functional grid-connected PV systems with load compensation under distorted and unbalanced grid voltages. Electric Power Systems Research 192:106918.

Ou R (2016) Cooperative control of SFCL and reactive power for improving the transient voltage stability of grid-connected wind farm with DFIGs. IEEE Transactions on Applied Superconductivity 26(7):1-6. 
Mortezaei A (2018) Grid-connected symmetrical cascaded multilevel converter for power quality improvement. IEEE Transactions on Industry Applications 54(3):2792-2805.

Renukadevi V and B Jayanand (2015) Harmonic and reactive power compensation of grid connected photovoltaic system. Procedia technology 21:438-442. 